\title{
Meditation and Exercise for the Common Cold? Who Knew?
}

Ann Fam Med 2012;10:iii. doi:10.1370/afm.1419.

T The Annals of Family Medicine encourages readers to develop a learning community of those seeking to improve health care and health through enhanced primary care. You can participate by conducting a RADICAL journal club and sharing the results of your discussions in the Annals online discussion for the featured articles. RADICAL is an acronym for Read, Ask, Discuss, Inquire, Collaborate, Act, and Learn. The word radical also indicates the need to engage diverse participants in thinking critically about important issues affecting primary care and then acting on those discussions. ${ }^{1}$

\section{HOW IT WORKS}

In each issue, the Annals selects an article or articles and provides discussion tips and questions. We encourage you to take a RADICAL approach to these materials and to post a summary of your conversation in our online discussion. (Open the article online and click on "TRACK Comments: Submit a response.") You can find

discussion questions and more information online

Ath attp://www.AnnFamMed.org/AJC/.

\section{CURRENT SELECTION}

\section{Article for Discussion}

Barrett B, Hayney MS, Muller D, et al. Meditation or exercise for preventing acute respiratory infection: a randomized controlled trial. Ann Fam Med. 2012;10(4):337-346.

\section{Discussion Tips}

Meditation and exercise have many benefits. This study tests their benefit for preventing the incidence, duration, symptoms, and dysfunction from acute respiratory tract infections.

\section{Discussion Questions}

- What questions are asked by this study?

- How does this study advance beyond previous research and clinical practice on this topic?
- How strong is the study design for answering the question?

- To what degree can the findings be accounted for by:

1. How patients were selected, excluded, or lost to follow-up?

2. How the main variables were measured?

3. Confounding (false attribution of causality because 2 variables discovered to be associated actually are associated with a 3rd factor)?

4. Chance?

5. How the findings were interpreted?

- What are the main study findings?

- How do the diversity and number of outcome and process measures affect your interpretation of the findings?

- How comparable is the study sample to similar patients in your practice?

- What would be required to make the intervention feasible in practice?

- What is your judgment about the transportability of the findings?

- Would you consider this study to be an efficacy or an effectiveness trial?

- What contextual factors are important for interpreting the findings?

- What is the biological and social plausibility of the findings? What mechanisms might be operating between the intervention and the observed outcomes?

- How might this study change your practice? Policy?

Education? Research?

- Who are the constituencies for the findings, and how might they be engaged in interpreting or using the findings?

-What are the next steps in interpreting or applying the findings?

- What researchable questions remain?

\section{References}

1. Stange KC, Miller WL, McLellan LA, et al. Annals Journal Club: it's time to get RADICAL. Ann Fam Med. 2006;4(3):196-197. http:// annfammed.org/cgi/content/full/4/3/196. 